\title{
Electron beam surface treatment. Part II: microstructure evolution of stainless steel and aluminum alloy during electron beam rapid solidification
}

\author{
R.G. Song ${ }^{\mathrm{a}, \mathrm{b}, *}$, K. Zhang ${ }^{\mathrm{a}}$, G.N. Chen ${ }^{\mathrm{a}}$ \\ ${ }^{a}$ Laboratory for Surface Modification, Materials Center, Institute of Mechanics, Chinese Academy of Sciences, \\ Beijing 100080, China \\ ${ }^{\mathrm{b}}$ Institute for Computational Science and Engineering, Ocean University of Qingdao, Shandong 266003, China
}

Received 20 June 2002; accepted 5 August 2002

\begin{abstract}
Surface rapid solidification microstructures of AISI 321 austenitic stainless steel and 2024 aluminum alloy have been investigated by electron beam remelting process and optical microscopy observation. It is indicated that the morphologies of the melted layer of both stainless steel and aluminum alloy change dramatically compared to the original materials. Also, the microstructures were greatly refined after the electron beam irradiation.
\end{abstract}

(C) 2003 Elsevier Science Ltd. All rights reserved.

Keywords: Electron beam; Rapid solidification; Microstructure; Stainless steel; Aluminum alloy

\section{Introduction}

It is well known that rapid solidification of alloys allows the extension of solubility limitation and refinement of microstructure as well as often leads to the appearance of metastable or amorphous phases. These effects could find use in a variety of application such as improving the mechanical and corrosion resistance properties of materials $[1,2]$. Therefore, it is of very important significance to understand fundamentally the

\footnotetext{
*Corresponding author. Present address: Research Institute of Biological Resources, National Institute of Advanced Industrial Science and Technology (AIST), 2-17-2-1 Tsukisamu-Higashi, Toyohira-ku, Sapporo 062 8517, Japan. Fax: +81-11-857-8984.

E-mail address: song.rg@aist.go.jp (R.G. Song).
}

microstructure evolution of materials during rapid solidification for the full development of rapid solidification processing technologies.

Recently, laser and electron beam surface remelting, as a newly developed rapid solidification technique, has been extensively used in surface modification of materials and studies on rapid solidification theories due to its unique advantages [3-9]. However, most current research works are focused on laser surface rapid solidification whereas the studies on electron beam surface rapid solidification are very rare so far. Based upon this, AISI 321 stainless steel and 2024 aluminum alloy were irradiated by electron beam, then the microstructure evolution of the molten pool during electron beam rapid solidification was studied. 


\section{Experimental}

The materials used in this study were AISI 321 stainless steel and 2024 aluminum alloy with the chemical compositions as shown in Tables 1 and 2, respectively.

Electron beam surface remelting experiments were carried out on a $60 \mathrm{~kW}$ moderate voltage electron beam welding machine made in Russia. The operation conditions for both stainless steel and aluminum alloy were as follows: $60 \mathrm{kV}$

Table 1

Chemical composition of AISI 321 stainless steel (wt \%)

\begin{tabular}{lllllllll}
\hline $\mathrm{C}$ & $\mathrm{Cr}$ & $\mathrm{Ni}$ & $\mathrm{Ti}$ & $\mathrm{Mn}$ & $\mathrm{Si}$ & $\mathrm{S}$ & $\mathrm{P}$ & $\mathrm{Fe}$ \\
\hline 0.097 & 18.17 & 9.58 & 0.42 & 1.48 & 0.47 & 0.007 & 0.033 & Bal. \\
\hline
\end{tabular}
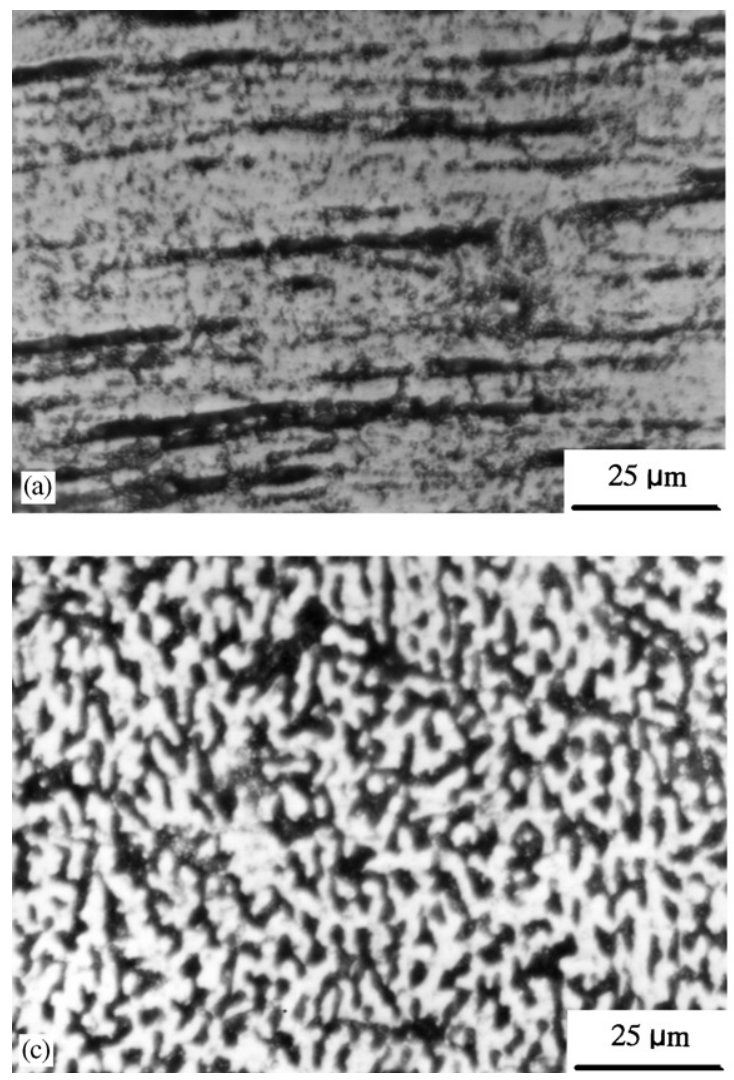

for accelerating voltage, $18 \mathrm{~mA}$ for beam current, $1.8 \mathrm{~m} / \mathrm{min}$ for scanning speed of the electron beam.

To comprehensively understand the morphologies of the resolidification microstructure, longitudinal section of the electron beam traces were cut as specimens for metallographic examination by optical microscopy (OM). All the specimens were ground and polished. Etching for stainless steel was performed using a solution containing $33 \mathrm{ml} \mathrm{HNO}_{3}$ and $67 \mathrm{ml} \mathrm{HCl}$ while etching for

Table 2

Chemical composition of 2024 aluminum alloy (wt \%)

\begin{tabular}{llll}
\hline $\mathrm{Cu}$ & $\mathrm{Mg}$ & $\mathrm{Mn}$ & $\mathrm{Al}$ \\
\hline 4.50 & 1.60 & 0.50 & Bal. \\
\hline
\end{tabular}
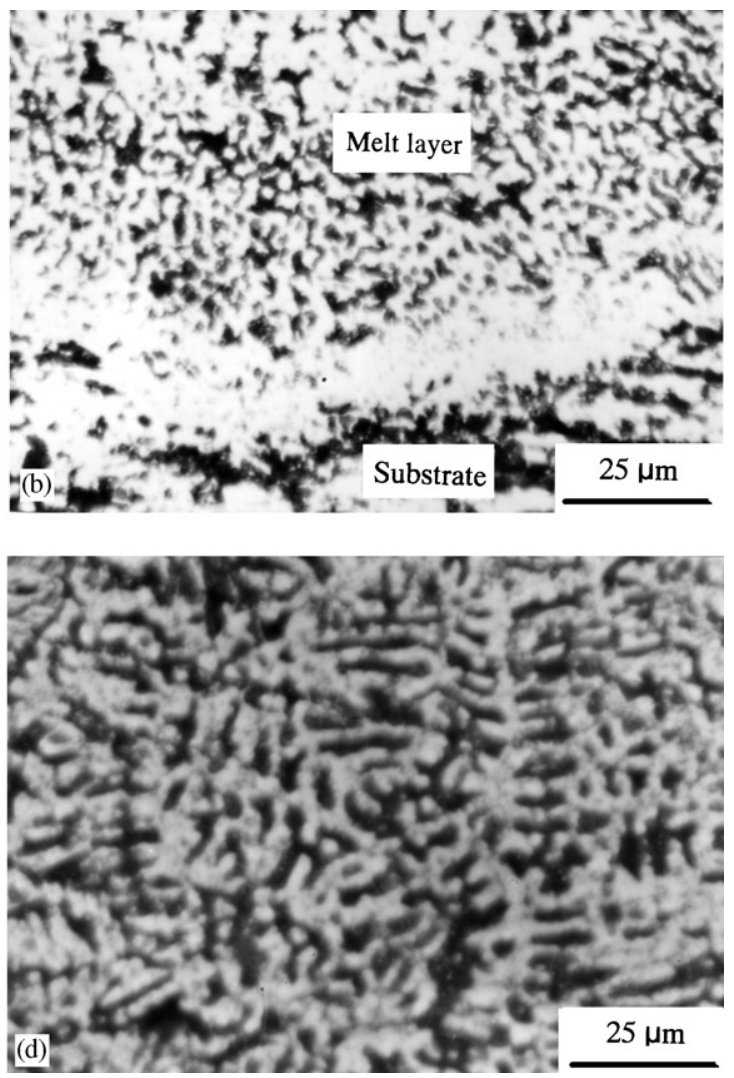

Fig. 1. Optical micrographs showing the microstructure of base AISI 321 stainless steel (a); and electron beam melted pool bottom (b); center (c); and surface (d). 
aluminum alloy was performed using a solution containing $0.5 \mathrm{ml} \mathrm{HF}$ and $95.5 \mathrm{ml}$ distilled water.

\section{Results and discussion}

\subsection{Microstructure of stainless steel}

Fig. 1 shows the microstructures of base AISI 321 stainless steel (Fig. 1a) and a single remelting track in longitudinal section (Fig. 1b-d). The structure of base stainless steel is typically hot rolling austensite, i.e. the corase austenitic grains were elongated along the rolling direction. From the boundary between the melted layer and the substrate to the surface, it can be seen that the microstructure morphologic transition of the planar crystal growth of a few micrometers at the maximum depth (Fig. 1b), $\rightarrow$ cellular/dendritic structures at the center of the melted layer (Fig. 1c) $\rightarrow$ random dendrites near the surface (Fig. 1d). According to the principles of solidification [10], the morphology of solidified material is controlled by the temperature gradient $(G)$ in the liquid near the advancing interface and by the growth rate $(R)$. With an increase in the ratio $G / R$, solidification morphology evolves from dendritic, to cellular, and to planar. In the present case, there exists a high positive temperature gradient at the side of liquid nearby the liquid-solid interface while just solidifying at the melted pool bottom, so that the liquid-solid interface moves forward very slowly, hence the ratio $G / R$ is rather big. Moreover, there exists strongly a composition supercooling at the melted pool bottom. Therefore, the solidification proceeds in planar crystal growth and a thin band at the melted pool bottom is formed, namely, a few micrometers white-bright layer. With the liquid-solid interface advancing from the pool center towards the pool surface, the growth rate significantly increasing, and the ratio $G / R$ decreasing, thus the planar crystal growth is broken down to take on a cellular/dendritic growth at the melted pool center and a dendritic growth at the melted pool surface. It should be clear that the random dendrites near the surface is mainly dependent on the irregular orientation of the substrate grain. Compared with that of the substrate, the microstructures of the melted layer are greatly refined.

\subsection{Microstructure of aluminum alloy}

Fig. 2 shows the microstructures of base 2024 aluminum alloy and a single remelting track in
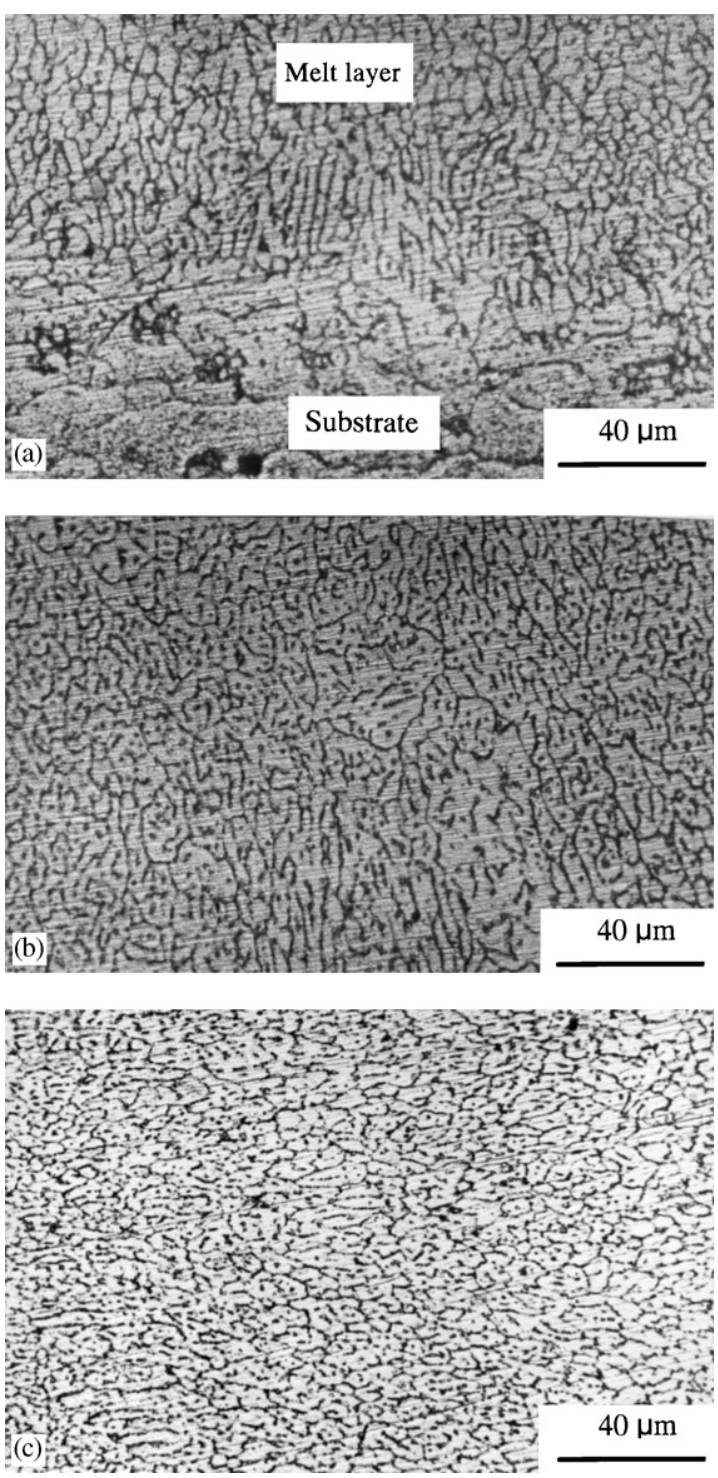

Fig. 2. Optical micrographs showing the microstructure of base 2024 aluminum alloy and electron beam melted pool bottom (a); center (b); and surface (c). 
longitudinal section (Fig. 2a-c). Typical epitaxial growth can be clearly seen in the melted layer. The morphologies of the resolidified grains varied with their position in the melted pool, i.e. cells near the interface between the melted layer and the substrate (Fig. 2a) $\rightarrow$ cells/dendrites at the center of the melted pool (Fig. 2b) $\rightarrow$ dendrites near the surface (Fig. 2c). This transition is also related to the variation in the ratio $G / R$. However, it is worth noticing that the usual planar crystal growth at the pool bottom did not occur in Fig. 2a, the reason maybe that $G$ at the start of solidification was not high enough to meet the planar crystal growth condition. At the melted pool bottom, the cells grew directionally along the heat flow direction because of high-temperature gradient existing; the preferred crystal orientation of different grains also showed remarkable influence on the direction of the growing cells. It can also be seen from Fig. 2a that the microstructure of the melted layer is much finer than that of base 2024 aluminum alloy.

\section{Summary}

The electron beam surface rapid solidification of both AISI 321 stainless steel and 2024 aluminum alloy induces significant changes in the microstructure morphologies of the modified zones compared to the starting materials. There are different solidification parameters at different positions in the melted layer, hence the morphologies selection of the modified zones at different positions exhibiting very different. The microstructures after electron beam irradiation have been much refined.

\section{Acknowledgements}

The financial aid of the National Natural Science Foundation of China under grant No. 59836220 is gratefully acknowledged.

\section{References}

[1] Song RG, He WZ, Huang WD. Surf Coat Technol 2000;130:20.

[2] Pan QY, Huang WD, Song RG, Zhou YH, Zhang GL. Surf Coat Technol 1998;102:245.

[3] Petrov P. Vacuum 1997;48:49.

[4] Ma D, Li Y, Wang FD, Li ZY. Mater Sci Eng A 2001;318:235.

[5] Dong H, Li XY, Bell T. J Alloy Compounds 1999;283:231.

[6] Yang S, Huang WD, Liu WJ, Zhong ML, Zhou YH. Acta Mater 2002;50:315.

[7] Li R, Ferreira MGS, Almeida A, Vilar R, Watkins KG, Mcmahon MA, Steen WM. Surf Coat Technol 1996;81: 290.

[8] Zhang K, Chen GN. Mater Sci Eng A 2000;292:229.

[9] Liu YC, Guo ZQ, Wang T, Xu DS, Song GS, Yang GC, Zhou YH. J Mater Process Technol 2001;108:394.

[10] Flemings MC. Solidification processing. New York, London: McGraw-Hill, 1974. 